\title{
In Reply: "Single Versus Multiple Hyperbaric Sessions for Carbon Monoxide Poisoning in a Murine Model"
}

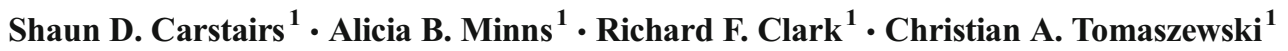

Received: 20 September 2016 / Accepted: 21 September 2016/Published online: 3 October 2016

(C) American College of Medical Toxicology 2016

In reply:

We thank Croll et al. for their thoughtful comments regarding our study. Our poisoning protocol was based upon a previously published protocol demonstrated to induce delayed neurologic sequelae in mice [1]. This has been validated in additional studies [2-4], so we believe that our model was appropriate.

Croll et al. state that "no significant difference was found in the outcome measures between the group of mice that were $\mathrm{CO}$ poisoned and received no treatment and the control group of mice that were not poisoned at all." With respect to stepdown latency (SDL), the difference between control and COpoisoned animals was not significant $(p=0.182)$. With respect to step-up latency (SUL), there was a statistically significant difference between control and CO-poisoned animals $(p=0.029)$, a difference that was not found once a Bonferroni correction was applied to account for multiple comparisons. As we described in our limitations, it could be that this correction was too conservative when comparing groups.

Unfortunately, the wide performance variability between our animals may have precluded us from finding potential differences between our subject groups. It is our hope, however, that our study will stimulate further discussion on the subject and will encourage others to work to determine the optimal treatment for CO-poisoned patients.

\section{Compliance with Ethical Standards}

Conflicts of Interest None

Sources of Funding None

\section{References}

1. Thom SR. Carbon monoxide-mediated brain lipid peroxidation in the rat. J Appl Physiol. 1990;68:997-1003.

2. Thom SR. Functional inhibition of leukocyte B2 integrins by hyperbaric oxygen in carbon monoxide-mediated brain injury in rats. Toxicol Appl Pharmacol (1985). 1993;123:248-56.

3. Thom SR, Bhopale VM, Fisher D, Zhang J, Gimotty P. Delayed neuropathology after carbon monoxide poisoning is immune-mediated. Proc Natl Acad Sci U S A. 2004;101:13660-5.

4. Thom SR, Bhopale VM, Fisher D. Hyperbaric oxygen reduces delayed immune-mediated neuropathology in experimental carbon monoxide toxicity. Toxicol Appl Pharmacol. 2006;213:152-9.
Shaun D. Carstairs

shaunc@yahoo.com

1 University of California San Diego, San Diego, CA, USA 